\title{
Immunological Studies in Arteritis of the Aorta and Great Vessels*
}

\author{
R. A. ASHERSON, M.B., CH.B., F.C.P.(S.A.) ; G. L. ASHERSON, D.M., M.R.C.P., M.R.C.P.ED., M.C.PATH. \\ V. SCHRIRE, M.D., M.SC., PH.D., F.R.C.P., F.R.C.P.ED., F.A.C.C.
}

Brit. med. F., 1968, 3, 589-590

\begin{abstract}
Cummary : Sera from 21 patients with arteritis of the $\checkmark$ aorta and great vessels were studied. The mean level of IgG, IgM, and IgA immunoglobulin was raised. The incidence of rheumatoid and antinuclear factor and antibodies to aorta, liver, and thyroid was not raised.
\end{abstract}

\section{Introduction}

Takayasu's syndrome or pulseless disease is also known as branchial arteritis (Koszewski and Hubbard, 1957), brachiocephalic arteritis (Gibbons and King, 1957), the aortic arch syndrome (Ross and McKusick, 1953), arteritis of the aorta and great vessels (Schrire and Asherson, 1964), and may have several causes. However, in most cases the cause is unknown. The protean nature of the disease, the raised gammaglobulin, the high erythrocyte sedimentation rate, and the occurrence of "rheumatic" manifestations either preceding or accompanying the arteritic phase led Hirsch et al. (1964) and Strachan (1964) to suggest that the tissue damage might be due in part to an autoimmune process.

We have investigated sera from eight of the patients reported in our previous series (Schrire and Asherson, 1964) and 13 new patients for immunological abnormalities. The present paper describes the finding of a raised level of $\operatorname{IgG}, \operatorname{IgM}$, and $\operatorname{Ig} A$ immunoglobulin.

\section{Materials and Methods}

Measurement of Immunoglobulins.-Immunoglobulins were measured by radial diffusion, using commercially available plates. These were calibrated with Behringwerke reference serum. The $t$ test was performed on the measurements of diameter.

Tanned Cell Test for Thyroglobulin.-Burroughs Wellcome formalinized tanned cells coated with thyroglobulin were used.

Complement Fixation Test.-The method used was that of Donelley (see Asherson, 1959). 2MHD ${ }_{100}$ of complement titrated in the presence of antigen was employed. Monkey liver and aorta and Burroughs Wellcome freeze-dried thyroid were used.

Rose-Waaler Reaction.-Burroughs Wellcome rabbit antisheep cell serum was employed. The rabbit serum was used at $1 / 4$ of the haemagglutinating dose.

Latex Fixation Test.-See Plotz and Singer (1956). A positive control was included.

Antinuclear Factor Test.-The indirect method was undertaken with snap frozen unfixed rat liver. A positive control was included. Antibodies to monkey aorta were sought with unfixed tissue and tissue fixed in absolute alcohol for 30 minutes or acetone for one minute. In all cases the sera were tested undiluted and patients' and control sera were eramined in parallel.

- From the Cardiac Clinic, Department of Medicine, University of Cape Town, and the Cardiovascular-Pulmonary Research Group, supported in the Department of Medicine by the Council for Scientific and Industrial Research, and the Department of Bacteriology, the London Hospital Medical College.
Ouchterlony Plate.-Liver and aorta were homogenized in $\stackrel{\mathbb{D}}{\circ}$ two volumes of $\mathrm{pH} 7.2$ phosphate-buffered saline and centri- $\infty$ fuged at $30,000 \mathrm{~g}$ for 30 minutes; $0.8 \%$ ionagar in phosphate- $\vec{O}$ buffered saline was used, and the plates were incubated for 14 days in the cold.

Nomenclature.-IgG, IgA, and IgM are the terms recommended by the World Health Organization (1964) to replace the old terms $7 S$ gammaglobulin, $\beta_{2} A$, and $\beta_{2} M$ macroglobulin.

\section{Results}

Serum Immunoglobulins.-There was a statistically signifi- cant rise in the serum level of the three major groups of $\mathcal{C}$ immunoglobulins in the patients with aortitis as compared with the controls. The Table shows that the level of IgG, IgA, and $\frac{\mathbb{D}}{3}$ IgM in patients with aortitis were $1,586(1,260), 396(275), \overbrace{\mathbb{D}}$ and 159 (111) mg./100 ml. respectively. The figures for the control patients are shown in parentheses. The rises of the $\vec{\theta}$ three classes are 26,43 , and $43 \%$. The probability of theseo findings occurring by chance was $<0.02,<0.02$, and $<0.05$, respectively.

\section{Tests for Antibodies}

The following tests showed no important difference between the patients with aortitis and the control subjects.

Complement Fixation.-Only one patient gave a titre greater than 8 against monkey liver. Three patients and two controls had titres of 8 against aorta. Three patients and one of the controls had titres against thyroid antigen of 8 or 16. $\frac{\overline{5}}{3}$

Haemagglutinating Antibody to Thyroglobulin.-One patient (No. 12) gave a titre of 25 , while one control subject (No. 8) $\frac{\delta}{3}$ gave a titre of 250 .

Rose-Waaler and Latex Fixation Test.-No serum in this 국 series showed an unequivocal positive latex fixation test (at $a \mathrm{~N}$ dilution of $1 / 20$ ) or Rose-Waaler reaction (at a dilution of $D$ 1/10). One patient (Case 20) and one control subject (No. 7) agglutinated coated sheep red cells to a titre of $1 / 20$, but there $N$ was some agglutination of the uncoated cells. One patient $N$ (Case 35) had a titre of 1/320 against sheep red cells.

Fluorescent Antibody Tests.-One patient had a weak posi-tive antinuclear factor test. Two patients and two controls $\frac{0}{\mathscr{D}}$ produced immunofluorescent staining of the liver, probably involving the sinusoids. The aorta showed bright blue auto- 0 fluorescence due to the elastic fibres. Staining of the adventitia 0 was seen with all the sera. No significant immunofluorescent $\mathbb{D}$ staining of the media or intima occurred.

Gel Diffusion.-No definite lines were seen against liver or aorta.

\section{Discussion}

These results show that patients with aortitis have a raised level of IgG, IgM, and IgA immunoglobulin as compared 
Level of Immunoglobulins, and Occurrence of Antibodies to Liver, Aorta, Thyroid, and Nuclei in Patients with Aortitis and in Control Subjects



The complement fixation results are expressed as the reciprocal of the highest titres giving 2 plus complement fixation. - Indicates negative results. A.N.P. = Antinuclear factor test.

f. These patients showed a reticular pattern in the liver in the immunofluorescent test.

with a control group of patients with functional disorders matched for age, sex, and ethnic group. They did not, however, show a raised incidence of autoantibodies of the organspecific kind found in the Hashimoto thyroiditis group of diseases or of the non-organ-specific kind found in systemic lupus erythematosus. No antibodies against aorta were found by complement fixation, gel precipitation, or immunofluorescence. This is in keeping with the negative findings of Hirsch et al. (1964), Strachan (1964), and Paloheimo et al. (1966). However, Ito (1966) in Japan found complementfixing autoantibodies in 12 out of 14 patients, and Maekawa and Ishikawa (1966) found antibodies against the outer layers of the aorta and pulmonary artery by tanned cell haemagglutination. The indirect antiglobulin consumption test was also positive. The reason for the difference between the Japanese and other series is unknown.

The finding of a raised level of immunoglobulin is in keeping with the observations of Ikeda (1966) and Sano and Aiba (1966). The former authors also found a raised level of alphaglobulins. The raised level of immunoglobulin suggests that these patients are exposed to antigenic stimuli which occur to a lesser extent or not at all in the control subjects. There are four main possibilities: (1) the disease may be due to an infection by a parasite or a micro-organism; (2) the disease may be due to an autoimmune process; (3) the disease may be due to antibody antigen complexes which selectively damage the aorta because of some other (unknown) agent which also acts on the aorta ; (4) the raised level of immunoglobulin may be due to an immune response to damage to the aorta and may throw no light on the cause of the damage.

We wish to acknowledge the help of Mr. Ian Wells and Mrs. S. Jordan, and the financial support of the Medical Research Council of Great Britain. We also wish to thank the Council for Scientific and Industrial Research and the Cape Town City Council for their financial support.

\section{REFERENCES}

Asherson, G. L. (1959). Brit. F. exp. Path., 40, 209.

Gibbons, T. B., and King R. L. (1957). Circulation, 15, 845 Hirsch, M. S., Aikat, B. K., and Basu, A. K. (1964). Bull. Fohns Hopk. Hosp., 1is, 29.

Ikeda, M." (1966). Fap. Circulat. Y. (En.), 30, 87.

Ito, I. (1966). Fap. Circulat. Y. (En.), 30, 75.

Koszewski, B. J., and Hubbard, T. F. (1957). Circulation, 16, 406.

Maekawa, M. and Ishikawa, K. (i966). Fap. Circulat. Ұ.'(En.), $30,79$.

Maloheimo, J. A., Julkunen, H., Siltanen, P., and Kajander, A. (1966). Acta med. scand., 179, 77.

Acta med. scand., 179, 77. (1956). Amer. 7. Med., 21, 893.

Plotz, C. M., and Singer, J. M. (1956). Amer. Y. Med., 21, 893, $2,101$.

Ross, R. S., and McKusick, V. A. (1953). Arch. intern. Med., 92,

Sano, $K_{\text {. }}$ and Aiba, T. (1966). Fap. Circular. F. (En.), 30, 63.

Strachan, $\ddot{R}$. W. (1964). Quart. $\dot{f}$. Med., 33, 57.

W.H.O. (1964). Bull. Wld Hlih Org., 30, 447. 